\title{
From the General to the Specific- Selecting the Target Memory
}

\author{
Liz Royle \\ Catherine Kerr \\ KR Trauma Support, Bolton, United Kingdom
}

\begin{abstract}
This article is an excerpt from the book Integrating EMDR Into Your Practice (Royle \& Kerr, 2010), which is a hands-on guide to facilitate the successful integration of eye movement desensitization and reprocessing (EMDR) training into therapists' practice while recognizing that trainees come from a range of theoretical backgrounds. This excerpt focuses on identifying the appropriate target memory and its related negative cognition (NC) in preparation for desensitization. Clients and therapists need to understand the rationale for selecting a particular target utilizing prioritization and clustering techniques. The importance of the belief system is discussed and methods of identifying the initial targets are offered, including the floatback technique. Many practitioners experience difficulty in getting the right NC, and methods for drawing this out are illustrated. Final preparations prior to desensitization are considered as well as the importance of addressing client anxieties and expectations. Throughout the excerpt, case vignettes are used to outline cautions and common pitfalls encountered by the novice EMDR therapist.
\end{abstract}

Keywords: EMDR; treatment plan; target memory; preparation phase; negative cognition; client anxiety

$\mathbf{T}$ he book Integrating EMDR Into Your Practice (Royle \& Kerr, 2010) is a hands-on guide to facilitate the successful integration of eye movement desensitization and reprocessing (EMDR; Shapiro, 2001) into therapists' practice. It recognizes that therapists attending EMDR trainings have a range of theoretical backgrounds and that they may feel challenged with the implementation of EMDR. The book identifies common pitfalls confronting therapists in each of the eight phases of EMDR and provides practical strategies to address these. This article is an excerpt of the chapter (Royle \& Kerr, 2010, pp. 79-107), which focuses on the assessment phase.

\section{Identifying Target Memories}

In EMDR, the treatment plan needs to identify specific targets for reprocessing. This will be a threepronged approach that includes the past memories that appeared to have set the pathology in process, the present situations that exacerbate this dysfunction, and the desired future response, emotionally, cognitively, and behaviorally (Shapiro, 2001). Clients and therapists need to understand the rationale for selecting a particular target utilizing prioritization and clustering techniques. Choosing the correct target can involve some detective work, but this will be time well spent.

\section{A Belief by Any Other Name}

Janoff-Bulman (1985) introduced the notion of an "Assumptive World Theory" to describe how individuals make assumptions about themselves and the world they live in. Our fundamental assumptions of "I am invulnerable," "the world is just and makes sense," and "I am basically a good person" may be "shattered" when a traumatic event is experienced.

According to McCann and Pearlman's (1990) Constructionist Self-Development Theory (CSDT), people give meaning to traumatic events depending on how, as individuals, they interpret them. These interpretations of the traumatic events may result in disruptions in their cognitive schemas, that is, the way

Editor's Note: This article is a modified reprint from Integrating EMDR Into your Practice (pp. 79-107), by L. Royle and C. Kerr, 2010, New York, NY: Springer Publishing. Copyright 2010 by Springer Publishing. Reprinted with permission. 
they view themselves and the world. Disruptions may occur in the psychological need areas of safety, trust, esteem, power, and intimacy.

Consider a police officer's personal experience of a violent assault during which he is injured and his colleague dies. Then, consider his potentially "shattered" assumptive world: "I am not invulnerable," "the world does not make sense, good people are not supposed to die," and "I don't believe I am a good person, I should have done something, I should have been able to prevent this." This shattering of assumptions can be one of the factors contributing to the cause of PTSD because of the anxieties that are raised when the world no longer makes sense.

As practicing clinicians, it is important to understand that our belief system permeates every aspect of our lives and helps us to create our identity. Consequently, when this belief system is shattered by a traumatic event it can have devastating implications for the individual. Cognitive behavioral therapists (CBT) will be familiar with terms such as core beliefs and cognitive schemas, but EMDR therapists come from diverse theoretical backgrounds and, although other therapies may not adopt this particular terminology, the notion is implicit within each theory.

Person-centered counseling (PCC; Rogers, 1995) refers to the "self-concept" describing the individual's self-image largely based on life experience and attitudes expressed by significant others, such as family, teachers, and friends. Rogers also refers to the "Ideal self," which is the way in which individuals would like to see themselves but which can differ radically from the self-concept. Again this can be formed through the internalized values of other people who tell these individuals how they should be rather than accept them for who they are.

Psychodynamic theory (PD), which originates mainly from Freud's study of human development, offers a variety of explanations. Thomas (1995) states that "internal worlds" are being created from birth (or even prebirth) by internalizing the external world. She suggests that at first the child's experience of the world is preverbal, and is often highly emotional. In addition, much of this early experience takes place in relationship with other human beings involving both verbal and nonverbal interaction. Consequently, this internal world begins to effect intention and behavior in the external world and shapes the meaning of later experiences. The key difference within the psychodynamic approaches is the emphasis placed on the respective roles of nature and nurture within this process of construction. Another assumption that psychoanalysts make is that we systematically distort our internal realities of the world so as to avoid anxiety (Thomas, 1995). This is carried out using "defense mechanisms" such as repression, denial, and projection; however, these are seen as largely unconscious processes.

So imagine for a moment the client who presents following a road traffic collision suffering from PTSD. During the history-taking phase you discover that her father had been a hard task master and the client had "never felt good enough" (identified as core belief, CBT, self-concept, PCC, or internal world, PD). Later in her life she had been married to a very dogmatic man who had very high expectations of her. The client had learned to cope with this by making sure everything was done to perfection and took control of every situation (also known as basic assumptions [CBT], ideal self [PCC], or defense mechanisms [PD]); in that way, she believed that no one would ever discover "the truth." Following the accident, although she was totally exonerated, her struggle concerned the fact that she was not in control, thus piercing her protective "mask" and revealing her core belief (CBT)/ self-concept (PC)/ internal world (PD) that she "wasn't good enough."

So, whether you call them beliefs, self-concepts, or internal worlds, they amount to the same thingthey are the window through which we see the event in relation to ourselves and others, in terms of responsibility, safety, control or choice, and selfesteem. Without some form of intervention, they are usually accepted without question and can be resistant to change. Furthermore, it is not always possible to pinpoint the belief. For example, if the events that lead to the belief occurred when the child was preverbal, all the client's symptoms may be somatic. Ogden, Minton, and Pain (2006) propose that all levels of information processing, that is, cognitions, emotions, or somatic reactions, are viable targets for therapeutic intervention, and suggest that because each level is connected, by addressing one level, if therapy is effective, it should have an impact on the other levels. Consequently, by targeting the sensorimotor tendencies directly, this can lower emotional arousal and help shift beliefs.

\section{Finding the Root of the Problem}

Schemas are often developed from childhood experiences, maintained and reinforced throughout life (Young, 1990). According to Janoff-Bulman, our earliest assumptions and representations generally have a far greater impact on our conceptual system than that which comes later. To fully understand the 


\section{Whatever You Do, Don't Do This ...}

Never negate your client's experience or belief system.

Helen had been severely assaulted at school when she was 12 . She recounted an incident when she was left bruised and bleeding and told by a teacher to sit in an empty classroom for an hour. Her therapist expressed surprise at this and suggested she had a distorted memory of the situation. This damaged the therapeutic relationship irrevocably.

Philips and Buncher (1999) proposed that as therapists, we have to take information on face value, because we only have the clients' word for whether their interpretation was real or imagined, true or false. However, they state that we can be certain that on that particular day, at that particular time, that person interpreted his thoughts in a certain way and from those thoughts a belief was created, a belief as to what that thought meant to him. They suggest that once an interpretation or belief has been given to a thought, it then becomes a reference point in the present tense, to enable the person to understand the world. At the same time, it becomes part of a structure that the unconscious mind will use to filter and sort all subsequent thoughts.

More important than the actual facts of Helen's experience was her interpretation of it.

impact of later traumatic events, it is important to know what preceded it. The primacy effect similarly emphasizes the undue influence of early thoughts and beliefs (Bowlby, 1980).

Establishing the starting point of EMDR is an important concept and can determine the effectiveness (or otherwise!) of the therapy. Explaining the reasoning behind this approach raises issues for both clients and therapists, particularly if the client has come to therapy to deal with one particular issue, and you, as the therapist are suggesting that it may be more helpful to work on an earlier target memory. Consequently, it is important that the client understands the nature of traumatic memory, how belief systems develop over time, and how this may contribute to sensitizing an individual to current triggers. This can be done in a number of ways, and the following metaphors may be useful.

\section{Gardening}

A simple way of explaining is by using the metaphor of the garden, by getting the client to imagine a large oak tree that has been growing for hundreds of years and the roots of which are damaging the foundation of the house. Chopping down the top of the tree would have no effect. However, if it were excavated from the roots, the foundations of the house could be stabilized. (It may help to draw this image.)

\section{Pyramid}

Memories and associated beliefs are built on each other over a lifetime. The strongest ones are formed in childhood and become the support for the rest of the pyramid. The bottom layers need to be the stron- gest to hold the upper layers in place securely. By removing shaky or unhelpful foundations, new, more adaptive ones can be created.

\section{Preparing for Desensitization}

\section{Choice of Dual Attention Stimulus}

DAS can sound intrusive and induce anxiety in the client. Even after the therapists think that they have explained everything in a calm, clear manner, some clients have surprising questions, for example:

What exactly are you going to do to me?

Will I have electrodes on my head?

Will it hurt?

Is it like hypnosis?

It is important to allow the client the space and permission to ask these questions. Therapists should familiarize the client at an early stage with the mechanics of DAS and allow them some control in choosing the technique to be used. Although studies are ongoing as to whether EMs are more effective than other forms of DAS, some studies such as those of Andrade, Kavanagh, and Baddeley (1997), Kavanaugh, Freese, Andrade, and May (2001), Sharpley, Montgomery, and Scalzo (1996), and Van den Hout, Muris, Salemink, and Kindt (2001) have demonstrated that eye movements decrease the vividness of memory images and the associated emotion, suggesting that they may make a more effective contribution to treatment by decreasing the prominence of the memory and its associated affect.

Although on the initial EMDR training course manual eye movement and tapping are often the 


\section{Whatever You Do, Don't Do This ...}

Catherine felt positive about her EMDR therapy up until the point where her male therapist demonstrated inducing DAS via tapping. He positioned his chair directly in front of her, knees touching, and proceeded to use his fingers to tap directly on Catherine's knees. This level of intimacy was very uncomfortable for her but, like many vulnerable clients, she felt unable to question the process and simply did not go back for further sessions.

methods demonstrated, there is a wide range of DAS machines available. Therapists often feel more comfortable using these, because they minimize repetitive strain and therapist fatigue and allow some physical distance between client and therapist. If using a machine to induce eye movements, therapists need to position themselves so that they can monitor the client's tracking. Introducing a machine can add to the client's anxiety, and he/she should feel equally comfortable with whatever process is used. We also need to reiterate that the client is in control and this is not a passive process. This is particularly important if an individual has been subject to abuse. A word of warning if using technology: be prepared for the day that the machine refuses to cooperate!

Whichever method is used, there should be collaboration over issues such as speed of DAS, distance of focus for eye movements, or volume for sound. Avoid the windscreen wiper effect! If the client needs to remove glasses or contact lenses for desensitization using eye movements, therapists should be aware that this can invoke feelings of vulnerability and should be sensitive to this.

If the therapist is not using a machine of some sort to deliver the DAS, the desensitization phase of EMDR can involve very close interpersonal proximity.

Always check the client's comfort with this close proximity. When using tapping on the back of a client's hands, therapists should always place some form of barrier between the clients' body and their hands, for example, a hard-backed book or cushion. This reduces any sensory connection traveling from the hands and onward.

Whichever method you choose, it is important to have another form of DAS and to prepare the client in advance for a potential change. This may be required, for example, if the client cannot focus on EM because of tears due to crying or tiredness. Some clients find it harder to retain a dual focus while watching lights or fingers and overly shift their attention to this external stimulus. Tapping or auditory stimulus can then become an option that is less distracting.

If you are using a machine, you should pay regard to your own positioning. You need to be able to monitor your client's nonverbal communication at the same time as being aware of the number of sets the machine is generating. With the traditional "ships passing" seating arrangement, the therapist can easily see the client's eyes moving from side to side. If a machine is promoting eye movements, you need to be able to check that the client is still retaining a dual focus and tracking the lights. Some machines will allow you to remotely control the duration and speed of DAS. Others will have a counter on the end of the light-bar displaying the number of DAS, and this is especially important for tactile and auditory stimulation where you may not have a clear indicator of numbers. Become familiar with the machine and, it may sound simple but, read the instructions and practice on a colleague.

\section{Case Example: Preparing to Have a Change of DAS}

Ursula always has a second method ready and prepares her client for a possible change.

"If we're starting with eye movements, I demonstrate how this would work and check out a comfortable distance, speed, and range. Then I let my client know that we have the option to change during desensitization and the possible reasons for this. I have a large hardcover book and I tell them that if we need to change I will pass them the book and ask them to put it across their knees with their hands on top. I show them how this would work and then demonstrate the tapping on the back of their hands. This means that if we do need to change we can do this with minimal interruption. This is especially important for clients when we are desensitizing abuse, and any unexpected movement or intrusion in their physical space could be scary. My clients also know they can ask for a change in DAS and that that's okay." 


\section{Common Pitfalls: Working With Machines}

"I was using headphones for auditory DAS and sitting across from my client. We started on the target image and I pressed the remote control. I was using a clock on the wall, the second hand, to give me an approximation of the number of DAS and when I stopped and asked the client what they noticed, they told me nothing had changed. After a couple more sets like this, my client asked whether they were supposed to be able to hear the beeps from the headphones. The remote control had stopped working and my client had been sitting there in silence and trusting I knew what I was doing!"

\section{Stop Signal}

Where clients have issues over control, emphasize that EMDR uses the brain's natural healing and remind them of the anxiety management you have previously discussed and that they can control these symptoms and stop at any point. The client should be reminded of the stop signal before each desensitization session. When choosing a stop signal, be clear about its nature. Having a verbal command "stop" may cause problems where the client is verbalizing an aspect of his or her memory, for example, telling a perpetrator to stop. Similarly, holding up both hands may be an articulation of trying to "push the trauma/perpetrator away." A single hand held up is the most common signal. There is a fine line between encouraging the client to maintain control of the process by stopping and allowing distress to peak and fall away naturally. This is where the therapeutic relationship and good preparation pay off. The client should feel able and supported in managing strong emotions yet empowered to stop if they feel in danger of being overwhelmed. A common metaphor is that of going through a dark tunnel — when things are at their blackest and scariest, that's the time to motor on through.

\section{Providing Clear Instructions}

Before starting DAS focusing on the target memory, it is important to give clear instructions to the client so as to provide as safe an experience as possible and address any performance anxiety. By this stage, you will have already introduced the concept of EMDR to the client. It is important to repeat this and give more detail about the potential client experience. As stated earlier, clients may have forgotten the original information or have remembered it in a distorted way. Later problems can often be side-stepped by ensuring that a client has the best possible understanding of what desensitization entails and what feedback you require. However, no matter how well the therapist explains this, there will be times that the client does not take on board the information.

A variety of explanations can be given and repeated. Many people use metaphors to understand processes, and they may automatically produce their own, which you can adapt to the EMDR process.

It can be hard to explain desensitization without setting client expectation. Here is another way of doing it:

At the beginning, we will start with thinking about a particular aspect of your target memory. That will involve

\section{Case Example: Word Association Game}

Carol sometimes uses this metaphor, finding that it helps clients not to censor seemingly irrelevant material that surfaces.

"Have you ever played the word association game-you know where a group of people start with one word and the next person has to say the first thing that comes into his or her head, then the next person responds to that one, very quickly and without consciously thinking about the link? And sometimes someone says something really bizarre and you think 'where did that come from?'

Well, desensitization can be like that sometimes. You may start with a particular target memory and your mind takes you to bizarre or unrelated memories. It's important just to notice where it's going and let me know. Try not to judge or censor the memory as it doesn't have to make sense. Just go with the flow. Trust that your mind will take you where it needs to go but sometimes it's like a magical mystery tour." 
the image that represents the worst part of the memory, a negative thought and the accompanying emotions and physical sensations. Once we start the eye movements (or other DAS), you may notice changes. This may be that the image changes or disappears or you remember different aspects of the incident. Sometimes, it is the emotion that changes-it may intensify or decrease or change, for example, from fear to sadness. You may notice new thoughts or different times in your life; other memories may surface. The physical sensations may change, for example, if you start with a headache, you may find this increases or reduces or changes location. The important thing to remember is that you cannot get this wrong. All you need to do is notice what is changing and tell me what you notice when I have stopped the eye movements. For some people, there will be a stream of fragmented images, thoughts, emotions, and physical sensations, for others the changes will be more subtle and we will have to look closely for what is changing. Everybody's experience will be slightly different and there is no right way for you to do this. Your brain will heal naturally in its own way.

Because desensitization the first time is such an unknown for clients, they can suffer from performance anxiety. No matter how well you think you have prepared your clients, they may have unexpressed fears about the actual desensitization:

What if I can't do it properly?

Will it change me?

Will I be aware of what's going on?

Will it make me go mad?

It is important to be aware of this and preempt questions as much as possible. Remind your client that there are no stupid questions, and if they have any worries at all they should express them. If you sense they are at all reluctant, explore this with them.

\section{Metaphors for Managing High Affect}

One of the most common fears for clients is whether they will be able to handle any strong emotions that arise.
Train

It can be helpful to compare the experience of memory processing with EMDR to being on a train journey. Ask the client to think about sitting on a train looking out of the window, and second by second the scenery changes. Sometimes the view will be colorful, sometimes it will be barren, certain things may stand out, you may see things you do not expect, but it always changes. EMDR desensitization is a similar process to this, with the images, thoughts, and sensations changing very quickly.

Video

Another way of helping the client to understand the way EMDR helps to process memories is the metaphor of a video. You can get them to imagine that they are watching the events unfold as if they were watching a film of the event. This also allows the clients to remove themselves slightly from the processing, particularly if the memory is eliciting high affect.

\section{The Splinter}

And finally, one of the ways to help clients manage and understand the strong emotions that may be experienced in EMDR desensitization is that of the splinter. Ask clients to imagine what would happen if they had a splinter in their finger and they chose to leave it there. Eventually it would become very sore and infected because it is not meant to be there, a bit like a traumatic memory. As such, EMDR is a metaphorical way of removing the splinter, which, initially, may hurt, however, as the splinter is cleaned out, it is allowed to heal so that when you touch it, it does not hurt anymore.

\section{Negative Cognitions and the Target Memory}

In choosing the target memory, therefore, the therapist and client need to determine the touchstone event, that is, the earliest memory linked to the current pathology.

\section{Case Example: The Hot Seat}

I give my clients the option to use a third chair in my consulting room for the actual desensitization part of sessions. My clients call this the Hot Seat and the majority prefer to use this.

We spend the first part of a desensitization session refining the target memory and associated NCs and so on. Then they move to the Hot Seat. Once we have reprocessed the memory (complete or not) they return to their original chair for a debriefing and relaxation exercise. My clients say it helps them to separate from what can be the hardest part of the session and to consider their experience objectively. They feel safer in their own chairs before desensitization and more relaxed in it afterward. The Hot Seat contains the experience and can be left behind. 


\section{Case Example: Socratic Questioning}

Presenting condition: Generalized anxiety.

Target memory: Bullying incident at school.

Therapist: What are the negative words that go best with that image?

Client: I should have run away.

Therapist: Because you didn't run away, what does that say about you?

Client: I got it wrong.

Therapist: What happens when you get it wrong?

Client: I get hurt.

Therapist: What does that say about you?

Client: I can't protect myself.

Therapist: What does that mean for you?

Final statement $=\mathrm{I}$ am in danger.

As you will have learned on your EMDR training course, the NC

should be in the present tense,

should be a statement about the self,

should be relevant to the current situation and the past

event(s) to be targeted,

is generalizable, and

produces affect that resonates with the target image.

Establishing the NC is an important aspect of the target memory, and it is probably the issue that is raised the most by novice (and experienced!) therapists. And, just to complicate matters, there may be more than one $\mathrm{NC}$ associated with an event.

From the moment the client walks into the room, therapists can be tuning their $\mathrm{NC}$ antennae and listening for examples of statements that lead to core beliefs; for example,

"That never works for me,"

"I was always the stupid one,"

"People always leave me,"

"I always get it wrong," and

"Something bad always happens."

These can give the therapist an indication of potential core beliefs that can be later refined into an NC.

Statements can be converted into a core belief using methods such as Socratic questioning. The NC should be as powerful as possible, that is, a behavioral statement such as "I should have done something" is not as powerful as a characterological statement such as "I am weak."

Depending on your terminology, predisposing factors are another way of determining threads or themes through the client's life.

Using another gardening metaphor, the NC can be considered as a weed running through various life events. If the top of the weed is removed, the person may feel some relief because the weed appears to have gone. However, if the roots remain, the weed will keep coming back time after time. By locating the roots (that is, the origins of the NC) and removing (targeting) them, the rest of the plant will shrivel and die.

Occasionally earlier memories are unclear, or the client is not aware of the memories that may be "feeding" the current issue. These can sometimes be identified by asking the client to do a lifeline, which can help the client and the therapist recognize patterns or themes; alternatively, the floatback technique can be used.

\section{Floatback}

As you will have discovered on your training course, the floatback technique is a way of eliciting an earlier memory if the client is having difficulty processing a

\section{Case Example: Negative Condition}

Misplaced feelings of shame and isolation accompanied Paul's NC of "I should have done something. It's my fault" when he considered the suicide of his colleague.

This mirrored feelings he had when at school. He had struggled in class while dealing with the breakup of his parents' marriage. He felt responsible for not being able to prevent their ultimate divorce. 


\section{Common Pitfall: Client Does Not Mention a Significant Earlier Event}

Angela was a survivor of the 2004 Asian Tsunami and had witnessed loss and devastation on a grand scale. During history taking, she reported a generally happy childhood and no significant previous events.

Her therapist proceeded with desensitization of the worst part of the disaster. The image was of a mother pleading with Angela to help her find her child. The NC was "I am helpless," and the emotions were anxiety, grief, and guilt. Despite initial reduction in Subjective Units of Disturbance Scale (SUDS), Angela made little progress. At this stage, her therapist decided to use the floatback technique on the NC and related emotions.

Angela immediately went to the memory of her baby brother's cot death and her mother sobbing hysterically on finding him. Angela was 6 at the time and had been jealous of the new baby. She had not revealed this event to her therapist because it still provoked guilt and she chose to avoid this. It had become a taboo subject.

Having explored the potential significance of the baby's death, Angela and her therapist agreed to target the earlier trauma. The desensitization of the first incident led to a later successful completion of the Tsunami trauma.

Sometimes clients take longer to build up the rapport and to begin to work collaboratively with their therapist. For a very few clients, it is only when they have experienced a desensitization session that they are able to open up and share additional information. This can have an impact on the case conceptualization.

current memory (Shapiro, 2001). It may be that the SUDS are not reducing despite the desensitization process, or the client does not know when the current difficulty first started. Depending on the particular scenario, you will either already have or will need to elicit the image, NC, and so on of the current situation, and this particular technique then allows the client to literally "float back" to the earliest memory he/ she has that involves the same thread. You will then process the earliest memory in the normal way.

If the client is having difficulty providing an $\mathrm{NC}$ despite all the above techniques, another method to use is to connect the client to the body sensations that they get when they think of the memory. Then ask them to imagine it as a shape and a color; once you have that image, ask, "if it had a voice what would it be saying?" This may enable you to pick up on the theme of the belief and then use the downward arrow technique or Socratic questioning to pinpoint the NC.

Once again, it is about using techniques that you are already aware of and integrating them into the EMDR protocol. Feeling de-skilled and anxious about EMDR is a normal part of the learning process where we become consciously incompetent. Embarking on the route to accreditation as an EMDR practitioner builds skills, providing a real sense of professional competence and can be easily achieved with determination, application, and, most importantly, good supervision.

\section{Case Example: Using the Floatback Technique}

Kate had been diagnosed with PTSD following a very difficult birth leading to an emergency cesarian section. With her therapist Sarah they had begun the assessment phase on the target memory of the delivery room being suddenly filled with medical staff and Kate's panic. Her worst image was of the delivery room door banging open and what seemed like dozens of people charging into the room.

Sarah: So now Kate, I want you to bring up the delivery room door banging open, the negative words "I am in danger," and just notice what feelings are coming up for you, where you are feeling them in your body ... and then let your mind float back to an earlier time in your life ... perhaps when you were a child or adolescent ... don't deliberately search for anything ... just let your mind float back and trust that it will take you to where it needs to go. It might be a big or a small memory . . . don't prejudge it ... just tell me the first scene that comes to mind where you had similar thoughts of being in danger and feelings of fear and panic.

(continued) 


\section{Case Example: Using the Floatback Technique (continued)}

Kate: I've gone to when I was about . . I I don't know, about 5 or 6 years old. I'm in the kitchen with my mum ... we're about to have our tea and my dad's just come home. He's really mad . . I think he'd been drinking again. He's swung the kitchen door so hard it nearly came off its hinges. I was terrified. It still makes me anxious now thinking about that.

Sarah: What picture represents the worst part of that incident to you now?

Kate: The violence of him slamming into the room and the panic in my mum's face.

Sarah: And what words go best with that picture to express your negative belief about yourself now?

Kate: I'm not safe-something bad is going to happen.

Sarah: When you bring up that picture of your dad slamming into the room, what would you like to believe about yourself now?

Kate: That he can't hurt me or my mum anymore. That it's over.

Sarah: And how true does that statement feel to you now on a scale of 1 to 7 , where 1 feels completely false and 7 feels completely true?

Kate: I know it's completely true but I still feel it's not ... it feels like a 1 or a 2.

Sarah: So when you bring up that picture of your dad slamming into the room and the words "I'm not safe," what emotion(s) do you feel now?

Kate: Scared, like butterflies in my stomach and sweaty palms . . . my head's gone a bit fuzzy as well (physical sensations given along with emotions).

Sarah: And on the scale of 0 to 10 , where 0 is no disturbance or neutral and 10 is the highest disturbance you can imagine...

Kate: It's a 9!

Sarah and Kate proceeded with desensitization of the childhood event prior to targeting the childbirth trauma. This was reprocessed in a subsequent session to good effect but Kate also gained a good deal of insight into reasons why this later event had been particularly distressing for her.

N.B. For this client, the floatback elicited the earliest memory related to the current issue, however, for other clients, there may be more than one floatback required to get to the root of the problem.

\section{References}

Andrade, J., Kavanagh, D., \& Baddeley, A. (1997). Eyemovement and visual imagery: A working memory approach to the treatment of post-traumatic stress disorder. British Journal of Clinical Psychology, 36, 209-223.

Bowlby, J. (1980). Attachment and loss. New York, NY: Basic Books.

Janoff-Bulman, R. (1985). Shattered assumptions, towards a new psychology of trauma. New York, NY: The Free Press.

Kavanaugh, D. J., Freese, S., Andrade, J., \& May, J. (2001). Effects of visuospatial tasks on desensitization to emotive memories. British Journal of Clinical Psychology, 40, 267-280.

McCann, L. I., \& Pearlman, L. A. (1990). Vicarious traumatization: A framework for understanding the psychological effects of working with victims. Journal of Traumatic Stress, 3, 131-149.

Ogden, P., Minton, K., \& Pain, C. (2006). Trauma and the body: A sensorimotor approach to psychotherapy. New York, NY: Norton.

Philips, G., \& Buncher, L. (1999). Gold counselling: A structured psychotherapeutic approach to the mapping and re aligning of belief systems (2nd ed.). Carmarthen, Wales: Crown House.
Rogers, C. (1995). A way of being (2nd ed.). Boston: Houghton Mifflin.

Royle, L., \& Kerr, C. (2010). Integrating EMDR into your practice. New York, NY: Springer Publishing.

Shapiro, F. (2001). Eye movement desensitization and reprocessing: Basic principles, protocols and procedures (2nd ed.). New York, NY: Guilford Press.

Sharpley, C. F., Montgomery, I. M., \& Scalzo, L. A. (1996). Comparative efficacy of EMDR and alternative procedures in reducing the vividness of mental images. Scandinavian Journal of Behaviour Therapy, 25, 37-42.

Thomas, K. (1995). The defensive self: A psychodynamic perspective. In R. Stevens (Ed.), Understanding the self. London, United Kingdom: Sage.

Van den Hout, M., Muris, P., Salemink, E., \& Kindt, M. (2001). Autobiographical memories become less vivid and emotional after eye movements. British Journal of Clinical Psychology, 40, 121-130.

Young, J. E. (1990). Cognitive therapy for personality disorder: A schema-focused approach. Sarasota, FL: Professional Resource Exchange.

Correspondence regarding this article should be directed to Liz Royle, 346 Blackburn Road, Egerton, Bolton, UK, BL7 9TR. E-mail: liz.royle@krtraumasupport.co.uk 